\title{
A Critique of Distance Learning as an Educational Tool for GIS in South Africa
}

\author{
Gregory D. Breetzke ${ }^{\mathrm{a}}$ \\ ${ }^{a}$ Department of Geography, Geoinformatics and Meteorology, University of Pretoria. \\ South Africa
}

\section{Abstract}

The advancement of distance learning as an educational tool for geographic information systems (GIS) has been at the forefront of educational development at tertiary institutions in the last decade in South Africa. Distance education is envisaged as a means whereby previously disadvantaged members of society, of all ages, can enrol either directly or remotely at a tertiary education institution at a reduced cost. The experiences of the UNIGIS distance learning programme at the University of Pretoria (UP) in South Africa have shown that logistical, technical and practical problems, including a high cancellation rate and the delayed completion of the programme in its entirety, abound when attempts are made to reproduce an internationally recognized distance-based course in a developing world environment. Critical success factors are identified and need to be fully satisfied before widespread GIS dissemination through distance education in South Africa can be achieved.

\section{Introduction}

Sustainability has been the focus of law and policy-makers since the inception of the African National Congress (ANC) government in South Africa in 1994. This focus has permeated throughout sectors of society including education as a whole, and higher education systems in part. Educators see the conception of distance learning and distance education in South Africa as instrumental in increasing the number of students that can gain a tertiary education at a reduced cost. The previous political dispensation's education policy prohibited black students attending the exclusive white universities. In 2004, South Africa celebrated its 10th year of democracy yet presently the black population, which represents over 80 per cent of the overall 
population in South Africa, still only represent 53 per cent of students enrolled in South African universities (South African Department of Education (DoE), 2003). There is, therefore, a need to increase access to higher education resources to the majority of the population in South Africa. Distance education is envisaged as a means whereby previously disadvantaged members of society, of all ages, can enrol either directly or remotely at a tertiary education institution. In a developing country distance education is desirable for a variety of reasons. First, distance education programmes increase educational access to four commonly excluded groups, including secondary school graduates who fail to gain admission to universities, married women with household responsibilities, geographically isolated or uprooted students (e.g. refugees), and economically disadvantaged communities (Saint, 1999). Second, it can relieve the financial burden of students being required physically to attend a university campus as well as all the logistical difficulties involved therein, and third, universities benefit from economies of scale as the number of graduates increases annually.

A geographical information system (GIS) is "an information system that is designed to work with data referenced by spatial or geographic coordinates" (Star \& Estes, 1990, p. 2). GIS-related distance education programmes were introduced at universities in South Africa in the mid-1990s. The International UNIGIS Distance Learning Programme, currently being offered at the Nelson Mandela Metropolitan University (NMMU) and at the University of Pretoria (UP), is among the GIS-based distance education programmes presently being offered in South Africa. UNIGIS is a network of universities cooperating since 1990 in the design and delivery of distance learning in GIS (UNIGIS Brochure, 2005). This paper chronicles the experiences of UNIGIS at UP, and will illustrate that, among others, the following problems were experienced: a high cancellation rate; delayed completion of the programme in its entirety; and backlogs at various software-specific modules within the programme. The question posed is: can a successful distance leaning environment, leading to eminent GIS education, be established and maintained in a developing country such as South Africa? 


\section{Distance Education}

Historically, distance education can be traced back to the 1700s and the beginnings of print-based correspondence study in the USA (Nania, 1999). It is believed that correspondence education, which is the earliest version of distance education, developed in the nineteenth century in Europe (Clark, 1999). Throughout the course of the twenty-first century, distance education's evolution has been predetermined by technological developments such as the advent of cable and satellite television in the 1970s and 1980s, and the Internet and other web-based educational tools in the 1990s. Distance education in southern Africa is not a recent development. The University of South Africa (UNISA) began a distance learning programme in 1946, while in Botswana, Kenya, Malawi and Zambia distance education initiatives have been in use for teacher training since the 1960s (John, 1996). Over 65 institutions provide distance learning in higher education in South Africa (Daves et al., 2001) with numerous universities having opened entire study courses on the Internet, and almost all mainstream universities giving students access to examinations schedules, class schedules, notice boards and evaluation marks online, for example, Students On-Line at UNISA (https://0-sol.unisa.ac.za.innopac.up.ac.za:443/) and the Virtual Campus at UP (https://www.up.ac.za/sos/app/template/Login.vm). UNISA is recognized as the leading university in South Africa providing distance education programmes with over 150,000 students registered in 2003 (DoE, 2003). Distance learning initiatives are also rapidly increasing in South Africa with participation rates at universities increased through distance education in the order of 40 per cent per annum since 1986 and nearly one-third of full-time equivalent (FTE) enrolments at universities being declared within distance education programmes (Glennie, 2004).

\section{GIS and Distance Education}

Longley et al. (2001) propose that a reduction in the price of computer technology in the 1980s led to an environment conducive to the establishment of the GIS software industry and opened up the use of the technology to all other 'spatial' disciplines. This development resulted in a significant demand in the 1980s and 1990s for persons who could manage a GIS. From the mid-1990s to the present, universities and colleges worldwide have developed various degrees programmes at the associates, bachelor's and master's level to address this growing demand (Wikle \& Finchum, 2003). GIS education has been a big success with an estimated 150,000 students studying the 
subject each year; and approximately 7000 institutions of higher education teaching or using GIS worldwide (Phoenix, 2004). South African universities have also responded to the international call for GIS education and currently most universities offer either a GIS degree or include substantial GIS components within a related degree or diploma. South African tertiary institutions have tended to adopt or develop their own curricula, based on the adaptations of those developed in North America and Europe (Zietsman, 2002). The majority of these programmes offered, however, were originally on-campus initiatives, with no real aspirations for the progression to distance education. The potential of distance education to "deliver a rigorous GIScience education" (Wright \& DiBiase, 2005, p. 93) was not lost on the GIS community in South Africa and educators were keen to use the successes of ESRI's Virtual Campus (VC); the Open University in the UK; and the international UNIGIS consortium to make GIS distance education programmes more readily available. With developing countries experiencing a rapid interest in GIS within the public and private sectors (Deckmyn et al., 1997), these distance-based GIS education resources are envisaged as a means whereby GIS can be disseminated not only to existing working professionals and disadvantaged tertiary students in South Africa but also to other students in developing countries. One of these educational resources is the UNIGIS Distance Learning Programme (http://www.UniGIS.org/), which was founded in 1990 but first introduced in South Africa in 1996 at UP. A review of literature regarding GIS and education reveals substantial interest in GIS distance learning, with researchers (Berdusco et al., 2000; Berdusco, 2004; Simonis, 2004; DiBiase \& Rademacher, 2005; Onsrud, 2005) all reflecting on the development, benefits and potential of GIS distance learning initiatives. One of the major themes of the Journal of Geography in Higher Education Symposium (Wright \& DiBiase, 2005) investigated distance education in geographic information science. For more information and web links to GIS and related distance education initiatives consult these references.

\section{Unigis: Introduction}

The International UNIGIS Distance Learning Programme is a franchised international distance-based programme, which is the leading world provider of GIS distance education. UNIGIS consists of a network of universities at 17 tertiary institutions in 14 countries worldwide and aims to provide students with the knowledge and skills necessary to build and manage a GIS within a range of applications. A student who 
wishes to register for the UNIGIS programme, which consists of the UNIGIS postgraduate diploma course and/or the master's programme, may apply for admission at any member institution worldwide. As the UNIGIS programme is supplemented by optional workshops on campus, most students apply to a member institution that is geographically nearest to them. For a student residing in sub-Saharan Africa, this is either the NMMU or UP, both located in South Africa. If a member institution accepts the student's application, the student becomes a distance-based independent learner who is related to the institution through the UNIGIS programme and is not accredited with the institution's degrees or certificates. An independent UNIGIS postgraduate diploma or master's certificate is awarded to the student on completion of the programme.

UNIGIS can be envisaged as a virtual campus, with students worldwide being supported by locally based staff using traditional and electronic learning resources (Heywood \& Cornelius, 1998). At present, over 1500 students from more than 40 different countries worldwide subscribe each year to one of the universities of the UNIGIS network to participate in the UNIGIS programme (Molendijk \& Scholten, 2005). The management of UNIGIS courses is carried out by an International Course Board (ICB), which the determines policies for all aspects of the course programmes including admissions, structure, content, monitoring, evaluation and assessment within a framework of the policies adopted by the Academic Boards of the collaborating tertiary institutions (UNIGIS Brochure, 2005). Each institution additionally has its own course committee that is responsible for the day-to-day operations of the course, and monitors and evaluates the UNIGIS programme at their institution within the framework set by the ICB. See also Heywood \& Cornelius (1998); Buckley \& Donert (2004) and Molendijk \& Scholten (2005) for information regarding the development and progress of the UNIGIS programme over the preceding decade.

\section{Unigis Structure, Content And Delivery}

The structure of UNIGIS is based on a series of distance learning modules delivered via the Internet, which includes module documentation, exercises and assignments, web links, discussion platforms and additional reading materials. Each member institution of the UNIGIS network is relatively free to adapt and customize the course 
documentation to support the needs of local students and to supplement the course resources with additional reading materials. The UNIGIS postgraduate diploma course comprises 10 compulsory modules of equal weighting and duration. Each module lasts for an average of six weeks with students required to complete between nine and 10 hours of work per week. The module titles are as follows:

- Module 1: GIS: An Overview;

- Module 2: Spatial Data Modelling;

- Module 3: Spatial Operations;

- Module 4: Database Theory I;

- Module 5: Data Acquisition;

- Module 6: Data Quality;

- Module 7: Concepts for Spatial Thinking;

- Module 8: Visualization;

(In addition, any one of the following 'choice' modules)

- Module 9: GIS and Organizations;

- Module 10: Project Management;

- Module 11: Remote Sensing and GIS;

- Module 12: Database Theory II;

(Final compulsory module)

- Module 13: GIS Project.

A more detailed overview of the academic content of these modules can be viewed at the UNIGIS website in South Africa (http://0tutor.petech.ac.za.innopac.up.ac.za:80/UniGIS/Postgrad/UNIGIS.htm). Modules 1 to 8, and module 13, are compulsory with the student given an option of completing any one of modules 9 to 12 in order to fulfil the course requirements. The study modules progress in numbered sequence from module 1 through to module 13 with the first module being issued online at the beginning of the course and subsequent modules being issued at set stages throughout the two-year duration of the course. Module 13 is the final compulsory module and consists of the implementation of a GIS project. The project gives the student the opportunity to apply the acquired knowledge and skills from the previous course modules in planning, implementing and managing a GIS. Students are required to read the course documentation on the 
Internet and/or download the documentation for use on their personal computers. Assessment for the course is in the form of self-assessed exercises that guide the student to relevant course material, and formal written assignments for each module. There are no conventional written exams. Presently, completed assignments are sent in as hard copy to the UP's UNIGIS Unit and are returned in hard copy to the students with attached comments and evaluation results. Assignment deadlines are set for each module at which time all students are expected to have submitted their work. Assessments of submitted work are undertaken by internal examiners, in consultation with external supervisors of collaborating institutions, and follow the numbered sequence of the modules. Ideally, the postgraduate diploma course should take two years to complete but may take longer if a student requests, and is granted, an extension of time to hand in an assignment or if his/her submitted work is unsatisfactory. A student who successfully completes the 10 modules obtains the UNIGIS postgraduate diploma and can register for the master's programme if he/she so desires.

The UNIGIS course at UP is delivered via the World Wide Web (WWW) using the WebCT commercial course management system. WebCT facilitates the creation of virtual educational environments through the Internet and has received favourable feedback from students worldwide (see Morss, 1999; Orsini-Jones, 2003; Pauley et al., 2004). WebCT provides several tools that allow UNIGIS to incorporate specialized distance learning technologies, hence making it easier and simple to use. Tools incorporated in the software for students and tutors include bulletin boards, chat rooms, a searchable and linkable glossary and online assignments.

\section{Unigis Evaluation}

The initial stages of UNIGIS were not encouraging with a relatively slow rate of progress of students coupled with a high number of dropouts. Results (Figure $\underline{1}$ ) indicated that of the 170 students who started the first UNIGIS course during the period 1996 to 1999, only 31 (18 per cent) completed all 10 required modules within the specified two years while 26 (15 per cent) cancelled their registration after completing a number of modules, while the majority of students 114 (67 per cent) were still at various stages of completion by 2000. 


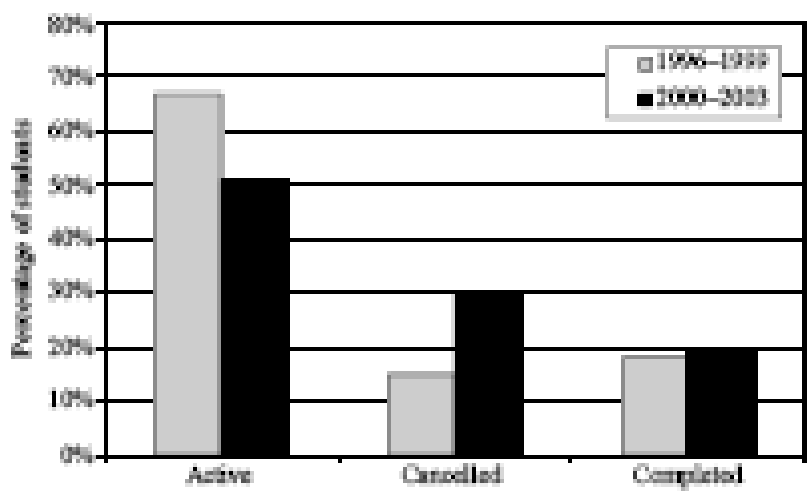

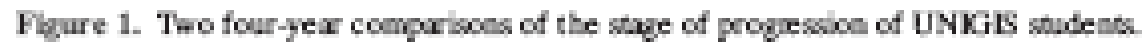

Figure 1. Two four-year comparisons of the stage of progression of UNIGIS students. The UNIGIS results of 2000 to 2003 (Figures 1 and 2) did not appear to elicit any great improvement. Post-1999 results indicated that of the 254 students registered for UNIGIS from 2000 to 2003, 47 (19 per cent) completed all the required modules within the specified two years while 76 (30 per cent) cancelled their registration. The greatest concern lies, however, in the large number, 131 (51 per cent) of students who were at various stages of completion of the course by 2004, with 13 students who registered in 1999 and 37 students who registered in 2000 still busy with the course in 2004. The overall trend indicated a proportionately lower number of students post1999 stalling over the completion of the course but an increasing number of cancellations (Figure 2).

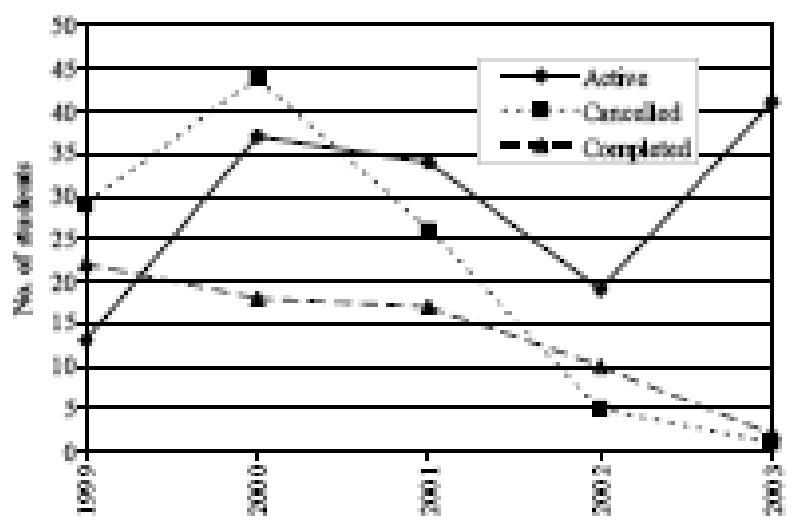

Flgure 2. Progressioe of UNKGIS shudends per year at vatious stages of complation from th99 to 2003 .

Figure 2. Progression of UNIGIS students per year at various stages of completion from 1999 to 2003. 


\section{Student Survey}

Van Helden (2000) conducted a survey of 215 students at various stages of completion of the UNIGIS course: 'Completed', 'Cancelled' and 'Active' (i.e. current and new students). His survey aimed to evaluate the progress of the students as well as to determine the students' perception of the UNIGIS programme at UP. The survey revealed that 85 per cent of 'Active' students who were falling behind schedule based the reason for their slow progress on a lack of time, while the other 15 per cent indicated a lack of motivation and discipline problems. The majority of 'Active' students indicated that the greatest obstacle in the completion of the diploma was modules where software knowledge is important, specifically Module 3: Spatial Operations, where students are required to review the course software, develop an analysis strategy for solving a spatial problem and implement a solution using the course software. Of those students who 'Cancelled' their studies, lack of time was again provided as the major reason for their cancellation but problems experienced with funding was also mentioned.

As far as career opportunities were concerned, 77 per cent of the respondents who had 'Completed' the course indicated that the qualification had helped them with their career. Similarly, a survey of students studying the UNIGIS course through a member institution in the UK found that students felt that the UNIGIS certificate was 'very important' for improving their career opportunities (Buckley \& Donert, 2004). The survey additionally indicated that 84 per cent of all four groups of students did not experience any problems entering the virtual campus, while 75 per cent of students found it easy to access and read the study materials and 67 per cent of students made use of the virtual communication tools available. In contrast, an initial global evaluation of the UNIGIS course by Heywood \& Cornelius (1998) revealed that a large majority of students do not make full, or any, use of electronic communications. This was a result of a number of factors including: the high costs associated with accessing the Internet, particularly in developing countries; the difficulty in accessing the Internet as a result of infrastructure, power supply and server problems; and other technical difficulties. The results of the local survey indicated that the problems experienced by the UNIGIS students at UP are related more specifically to a lack of time, a lack of motivation to make time to study, and a lack of funding than to access to information infrastructure and associated difficulties. 


\section{Experience of the Author}

It is noted by the author that students study the UNIGIS course material in order to pass an examination or written assignment and not to incorporate what they have learnt into their formal workplace. This problem experienced within the UNIGIS programme is not unique to GIS-related distance learning programmes in South Africa as Bosman \& Frost (1996), while investigating the effectiveness of distance learning to educate police officers, concluded that significant progress was not possible through traditional distance education. Their findings outlined the fact that students only learnt in order to pass an examination, rather than focusing on acquiring the competence needed to be effective in their workplace. UNIGIS has filled the void as far as theoretical knowledge of GIS is concerned, although issues of practical competence still need to be addressed. It is also, however, acknowledged that the UNIGIS programme in itself is primarily aimed at individuals with practical knowledge in information technology and management. The findings of the student survey, supplemented with the experience of the author in assisting and tutoring the UNIGIS programme at UP, highlight the concerns and illustrate the uncertainty regarding the current success or failure of UNIGIS in South Africa.

\section{Critical Success Factors for Distance-based GIS Education in South Africa}

GIS is often claimed as a unique field of interest and expertise; the educational challenge lies in establishing a unique distance-learning environment for developing countries in which the field can be adequately expressed. Messina (2002) identifies several critical success factors in distance education that can be considered for distance-based GIS education initiatives in South Africa.

\section{Student-Faculty Communication}

Student-faculty interaction is inherently limited in distance learning environments; but the limited communication that exists within the course is essential for its success. The virtual communication tools of email, message and notice boards, among others, play an important role in the divulging of information to students and hence should be utilized frequently. The style of interaction, and whether or not that style meets the needs of the students, should also be such that the student can express his/her sentiments without inhibition. Failure to adhere to these requirements can make it 
easier for the students to perceive that the faculty running the course do not care for the needs of the students and are not maintaining the course adequately (Hailey et al., 2001). GIS distance learning modules dealing, in particular, with certain software developments and issues can provide backlogs to students' progress unless timely responses are elicited from the online faculty. It is, therefore, essential that an open communication channel be established between the faculty and the students through email and live chats within the distance-learning environment.

\section{Student Interaction}

Student interaction within GIS distance education should be encouraged and facilities made available to the student to communicate with fellow students through message boards and chat rooms. Student interaction should, however, be limited to abide within the stated rules and regulations of the study course. The UNIGIS course is structured in such a way that students submit individual assignments on completion of course modules. Written examinations were attempted at UP in 2003 as a means of evaluation for students enrolled in UNIGIS to reduce the potential problems of collusion. Students' interaction in this regard is detrimental to the proposed outcome of the course, yet for distance education student interaction is important to enhance the educational process. The emphasis must be to encourage interactive mechanisms that allow for effective, but fair, interaction between students, be they virtual mechanisms (e.g. chat rooms) or real mechanisms (e.g. workshops).

\section{Accessibility of Library and/or Research Materials}

A study by Liu \& Ye Yang (2004) found that distance-based students' usage of information sources is predominantly governed by the principle of least effort. The implication is that students access those resource materials and documents that require the least effort to ascertain, leading to a preference for online information, which offers greater geographical and temporal convenience. Students taking distance-based courses typically live in areas that are geographically remote from university libraries and computer laboratories. It is, therefore, vital that students be given access to both physical and virtual facilities providing research materials, such as university libraries (physical and virtual) and computer laboratories. Reading materials are provided in the modules within the UNIGIS course material but these are insufficient to complete comprehensive assignments, especially those involving current GIS initiatives and 
future technological developments. The need exists, particularly at UNIGIS member institutions in developing countries, to improve accessibility to physical libraries, computer laboratories and other locations that provide resources for the students.

\section{Computer Skills}

Computer literacy is sine qua non for GIS competence. A distance-based programme such as UNIGIS requires some form of computer literacy, yet this critical success factor is probably the most contentious of all in South Africa. While WebCT software functionality extends to such impressive distance education tools as notice boards, chat rooms, e-books and online quizzes, these tools help little when they are not being utilized due to a lack of computer literacy. Experience at UP has shown that the basic functions such as downloading, copying and pasting are not software obstacles for the students; however, certain software specific modules within the UNIGIS programme, such as Module 3: Spatial Operations, and Module 4, Database Theory I, which require advanced computer literacy, are proving to be obstacles. The student survey of Van Helden (2000) found that the level of general computer literacy does not seem to have a significant influence on the success rate of the students completing the UNIGIS course. A backlog at certain software-specific modules however, implies that while basic computer literacy skills may be sufficient to access and download the course materials it does not suffice when UNIGIS modules involving computer-aided design (CAD), database management or GIS software-specific modules are attempted. The problem of computer literacy has been identified at UP in general, where all firstyear students studying any UP degree or programme are required to register for a basic computer literacy course in their first year of study, regardless of the study programme selected by the student.

\section{Computer Requirements}

The computer hardware requirements for UNIGIS are substantial. GIS distance learners require personal computers that should be at the upper end of the information technology (IT) spectrum, and be IBM compatible. In order to access course materials and communicate electronically, students require a modem to connect to the telephone network, a service provider that will send and collect email and access to the WWW. The initial question that must be asked in this regard is whether or not students in South Africa have readily available access to computer hardware and software. 
According to the last census taken in South Africa in 2001 only 42 per cent of households have access to a telephone line. Only 8.6 per cent of the population has a computer in their household, and of that group half are white households, even though they constitute only 12.5 per cent of total households; 98.2 per cent of black households do not own a computer (Statistics South Africa (SSA), 2003). In addition to the limited computer access (not to mention Internet access) of users in South Africa and Africa more generally, other secondary problems surface such as inadequate bandwidth (speed of Internet connection), unreliability of telephone lines and telecommunication companies, accessibility to and in rural areas, and the high costs for telephone and provider fees (Längin \& Ackerman, 2003). However, access to information infrastructure, and other telecommunication problems referred to above were not reported as being major problems experienced by the students in the findings of the student survey. These statistics reveal more importantly that in order for GIS distance education initiatives to be successfully accessible and implemental to the broader community in South Africa, basic information and communications technology needs to be improved.

Wright \& DiBiase (2005) outline access to software as being a challenge most unique to GIScience distance education. This challenge extends specifically to distance education initiatives in developing countries. The computer software requirements for UNIGIS, for example, are substantial. Study modules within UNIGIS and other distance-based GIS courses are software specific and require GIS packages such as IDRISI, MSOffice and ArcGIS. Student versions or demonstration versions of the software are made available with time stamps at reduced rates. Specifically, it is the responsibility of the student to have access to a licensed or evaluation version of the software. The computer hardware and software requirements place a further financial burden on the student and if these constraints cannot be overcome it forces the student either to attend the university computer lab to conduct practical assignments/exams and learn the software or to drop out of the course - a point that is supported in the student survey where a lack of funding was highlighted as a major reason for the cancellation of students conducting the UNIGIS course.

\section{Student Training}


Student training refers to the extent to which prospective students are trained before the implementation of the course of study (Messina, 2002). Training involves the education of the students in the method of distance learning, usually the software used in the dispensing of course material and assignments. Optional student training does occur within UNIGIS at UP through the scheduling of workshops at intermittent periods during the course of the two-year UNIGIS diploma. Typically these workshop sessions address any problems students may be encountering within the programme and provide them with an opportunity to establish contacts with fellow students. As a result of these workshops being optional they are often restricted to those students who are financially able to incur the costs of travelling to the workshop venue, the cost of accommodation at the venue and living expenses, all of which are not covered in their tuition fees. The UNIGIS programme takes place in an asynchronous learning environment, which allows the student to adapt to the pace of learning in order to suit his or her own particular requirements. A need exists to establish online training programmes before and during the UNIGIS course at which time students may convey their thoughts or uncertainties online regarding certain aspects of the programme including, for instance, the instructional telematic software, such as WebCT or course documentation.

\section{Conclusion: Future Uncertain}

There are few hard data available with which to assess the penetration and sustainability of GIS in developing countries (Hall, 1999). Developing countries experience different challenges from developed countries in terms of establishing a distance-learning environment that benefits all students in the long term. Shrestha (1997) identifies the three important barriers to distance education or learning in developing countries as being, first, a lack of resources needed for meaningful development and sustenance of technology-based learning, second, a lack of infrastructures (which includes information and communication hardware systems) to support modern technologies in least developed and/or low-technology countries, and third, a lack of recurrent funding necessary to acquire or develop appropriate software and courseware on a continuous basis, and maintain, service and replace the equipment. These fundamental problems are reproduced when international distancebased programmes, such as UNIGIS, are exported to developing countries, and far from improving the quality of educational life or expectations of the powerless and 
the poor, the application of technology often reinforces the problems of inequality (Hellman, 2003).

UNIGIS student progression figures illustrate the difficulty in initiating an internationally developed distance course at UP, with a high failure rate of students coupled with a student majority who are still 'Active' on the course long after the maximum two-year time period has elapsed. Critical success factors, identified earlier, can be used to establish a more secure distance-learning environment, which would lead to the education of GIS individuals in the public and private sector. The fact that distance-based GIS education has, however, commenced in South Africa is important to the Geo-information Society of South Africa (GISSA) and other GIS organizations in South Africa for whom advocating the importance and awareness of GIS in government and local parastatals is of primary concern. The future of GIS education in South Africa, however, revolves primarily around the ability of GIS educators, government and the broader GIS community in South Africa to overcome the root problems regarding a lack of funding and basic infrastructure before widespread GIS dissemination through distance education can be achieved.

\section{References}

- 1.

- 2 .

- 3. Bosman, W. and Frost, D. (Pagon, M. ed.) (1996) Policing and distance education in South Africa: a process in transformation. Policing in Central and Eastern Europe: Comparing Firsthand Knowledge with Experience from the West pp. 615-626. College of Police and Security Studies , Ljubljana, Slovenia

- 4. http://www.eurodl.org/

- 5. http://www.nwlink.com/ donclark/hrd/history/correspondence.html

- 6.

- 7 .

- 8. DiBiase, D. and Rademacher, H. J. (2005) Scaling up: faculty workload, class size, and student satisfaction in a distance learning course on Geographic 
Information Science. Journal of Geography in Higher Education 29:1, pp. 139-158. [informaworld]

- 9 .

- 10. Hailey Jr, D. E., Grant-Davie, K. and Hult, C. A. (2001) Online education horror stories worthy of Halloween: a short list of problems and solutions in online instruction. Computers and Composition 18:4 , pp. 387-397.

- 11. Hall, G. B. (1999) GIS education and infrastructure challenges and problems in emerging countries. Transactions in GIS 3:4 , pp. 311-319.

- 12. Hellman, J. A. (2003) Distance education: its advantages and shortcomings. United Nations (UN) Chronicle 40:4 , p. 47.

- $\quad$ 13. Heywood, D. I. and Cornelius, S. C. (1998) - Developing a virtual campus for UNIGIS: An international distance learning programme in GIS. Paper adapted from a presentation at the BITE98 Conference in Maastricht, The Netherlands, March 1998

- 14. John, M. (1996) Distance education in sub-Saharan Africa: the next five years. Innovations in Education and Training International 33:1 , pp. 50-57.

- 15. Längin, D. and Ackerman, P. (2003) Internet and forestry in South Africa-how does it fit together?. Wood SA and Timber Times 28:4 , pp. 3032.

- 16. Liu, Z. and Yang, Z. Ye (2004) Factors influencing distance-education graduate students' use of information sources: a user study. Journal of Academic Librarianship 30:1 , pp. 24-35.

- $\quad$ 17. Longley, P., Goodchild, M., Maguire, D. and Rhind, D. (2001) Geographic Information Systems and Science John Wiley , Chichester

- 18. Messina, B. A. (2002) Distance learning: An option for your future?. Journal of PeriAnesthesia Nursing 17:5 , pp. 304-309.

- 19.

- 20. - Proceedings of the $1^{\text {st }}$ Annual WebCT Conference on Learning Technologies, Vancouver, Canada.

- 21. http://www.nyadulted.org/dislrn6.htm

- 22. Onsrud, H. J. (2005) Web-casting of Geographic Information Science graduate courses. Journal of Geography in Higher Education 29:1 , pp. 123137. [informaworld] 
- $\quad$ 23. - Proceedings of the $5^{\text {th }}$ Annual WebCT Conference on Learning Technologies, San Diego, United States.

- 24. - Proceedings of the $6^{\text {th }}$ Annual WebCT Conference on Learning Technologies, Orlando, FL.

- 25.

- 26. Saint, W. (1999) Tertiary Distance Education and Technology in subSaharan Africa World Bank, ADEA Working group on higher education , Washington DC

- 27. Shrestha, G. (1997) Distance Education in Developing Countries United Nations Development Programme , New York — Info 21/Information and Communications Technologies for Development

- 28.

- 29. South African Department of Education (DoE) (2003) Unduplicated Headcount of Enrolled Students According to Race, Gender, Home Language and Qualification Type Higher Education and Planning Directorate , Pretoria

- 30. Star, J. and Estes, J. E. (1990) Geographical Information Systems: An introduction Prentice Hall , Englewood Cliffs, NJ

- 31. Statistics South Africa (2003) Census 2001-Census in brief Statistics South Africa , Pretoria - Report no. 03-02-03

- 32. UNIGIS Brochure (2005) UNIGIS Postgraduate Diploma Course Guidelines Port Elizabeth Technikon, South Africa

- 33. - Paper presented at the $2^{\text {nd }}$ European GIS Education Seminar, Budapest, Hungary.

- 34. Wikle, T. A. and Finchum, G. A. (2003) The emerging GIS degree landscape. Computers, Environment and Urban Systems 27 , pp. 107-122.

- 35. Wright, D. J. and DiBiase, D. (2005) Distance education in Geographic Information Science: symposium and an informal survey. Journal of Geography in Higher Education 29:1 , pp. 91-100. [informaworld]

- 36. Zietsman, H. L. (2002) Geographic Information Science in South Africa. South African Geographical Journal 84:1 , pp. 30-37. 